\title{
Expectations of life and health among spinal cord injured adults
}

\author{
Mary Ann McColl ${ }^{1}$, Janice Walker ${ }^{3}$, Paul Stirling ${ }^{3}$, Russell Wilkins ${ }^{4}$ and Paul Corey ${ }^{2}$ \\ ${ }^{1}$ Queen's University, Kingston, Canada, ${ }^{2}$ University of Toronto, Toronto, Canada, ${ }^{3}$ Lyndhurst Spinal Cord Centre, \\ Toronto, Canada, ${ }^{4}$ Statistics Canada, Ottawa, Canada
}

\begin{abstract}
While our understanding of aging and mortality in spinal cord injury is evolving, precise estimates are still not available for expectations of life and health following a spinal cord injury. In order to derive these estimates, information about mortality and health must be combined into a single estimate. Health expectancy estimates have been widely used in the literature of the last decade to try to understand the relationship between population health and survival, both in the general population and in special populations. This study brought the benefit of this methodology to the question of long-term survival following spinal cord injury. Specifically, the study aimed to calculate life and health expectancy in a population of spinal cord injured individuals; and, to estimate the effect of factors associated with survival and health. The study involved a retrospective cohort, all of whom sustained a spinal cord injury between the ages of 25 and 34 years, and between 1945 and 1990. The study predicted a median survival time of 38 years post-injury, with $43 \%$ surviving at least 40 years. These findings suggest an increase in life expectancy of about 5 years over previous research on the same cohort. ${ }^{1}$ Factors affecting survival were age at injury, level and completeness of lesion. Expectations of health found in the present study are similar to those found in studies of the general population. ${ }^{2}$ This study showed seven remaining years of poor health expected at injury, and five remaining years expected at 40 years post injury, presumably occurring at the end of life.
\end{abstract}

Keywords: spinal cord injury; mortality; health expectancy; aging; health

\section{Introduction}

Through the recent work of a number of North American and British researchers, a clearer picture is now emerging of the survival experience of people who have sustained a traumatic spinal cord injury. Studies of long-term survival show considerable agreement about the life expectancy of someone with a spinal cord injury and the factors affecting survival.

In 1961, Breithaupt and colleagues published the first accounts of long-term survival of traumatic paraplegics, and found that on average, individuals could expect to live to 55 or 60 years of age, depending on their age at the time of injury. ${ }^{3}$ In two subsequent studies, no real improvements in life expectancy were found. ${ }^{4,5}$ However, a fourth study completed in 1980 showed that while mortality in the spinal cord injured population was still significantly worse than that for the overall Canadian population, improvements in life expectancy were detected such that people who are paraplegic were found to be living about a decade longer $\left(65-69\right.$ years of age). ${ }^{1}$

Correspondence: MA McColl, $\mathrm{PhD}$
While a number of other authors have provided precise and detailed information about short and medium-term survival, ${ }^{6-13}$ only very recently has more modern information become available about long-term survival. Whiteneck and colleagues ${ }^{14}$ examined a sample of 843 people from the UK with spinal cord injuries of at least 20 years duration. Members of this cohort had experienced their injury between 1945 and 1970, and all had survived at least 1 year. Using life table methods, Whiteneck and colleagues show that the mean survival time for their sample was 32 years post injury, with $53 \%$ of people surviving beyond 30 years and $35 \%$ beyond 40 years. Given an average age of injury of about 30, this study suggests that survival times are still considerably below normal, as confirmed by standardized mortality ratios between 1.6 and 9.2, depending on age and time since injury.

Samsa and colleagues ${ }^{15}$ also addressed the question of long-term survival following spinal cord injury. In a cleverly designed study, they confronted the persistent controversy about whether or not a disparity exists between life expectancies of spinal cord injured and able-bodied populations. They found in a 20 year study (between 1968 and 1988) that spinal cord injured veterans had a mean life expectancy of 39 years post 
injury, whereas non-disabled veterans could expect 48 more years and members of the general population could expect 46 more years. This estimate is higher than that from the Whiteneck study, probably because of the more recent experience of this cohort, all of whom were injured after 1967.

Factors affecting mortality are remarkably consistent throughout the literature. Age at injury is perhaps the most consistent predictor, with those injured at younger ages experiencing better survival outcomes. $14-16$ Year of injury is also an important predictor of survival, with those injured more recently experiencing better outcomes. ${ }^{14,17}$ Research suggests that changes in acute treatment and rehabilitation in the early 1970s brought about a significant decrease in premature mortality, especially from respiratory and renal diseases. 1,18,19 Level and completeness of lesion were also found in some studies to be important predictors of mortality. ${ }^{14,16,17}$ However, Samsa's ${ }^{15}$ more recent cohort showed no effect of level or completeness of lesion on predictions of mortality. They explain that as causes of death for spinal cord injured people approach those of the general population (cardiovascular disease and neoplasms), level and completeness of injury diminish in importance. Whereas causes of death in earlier research were closely related to the injury itself (sepsis, respiratory or renal disease), the most prevalent causes of more recent deaths are less likely to be related to the spinal cord injury, and more likely to be chronic disesaes related to heredity, lifestyle and other factors.

Thus it appears that survival following spinal cord injury is increasing, although it is not yet at the level of the general population. What is missing from these analyses, however, is information about health experienced during the period of increased survival. If health at advanced ages is severely compromised, then survival statistics become somewhat less meaningful, and increases in survival less gratifying.

This same discussion permeates the literature on aging and mortality in the general population, where increases in survival have also been experienced over the past several decades. The most optimistic projections state that as survival increases, mortality continues to be compressed into the last few years of life, thus most people experience longer periods of healthy life. The most pessimistic projections, on the other hand, suggest an expansion of morbidity to fill the increased survival period. Chronic diseases will continue to have their onset at the same age (or even earlier, given improved methods of detection), thus the result of longer survival is simply living longer in a morbid condition. Alternately there is an intermediate prediction, which suggests that longer survival, even if accompanied by some increases in morbidity, must render some benefits in terms of additional years of healthy life. ${ }^{20-22}$ Clearly more information is needed about the conditions of life as people age in order to interpret the meaning of increasing survival statistics.
In the general population, the health picture of older people is more positive than one might expect. Data from the General Social Survey ${ }^{23}$ show that, while selfrated health does worsen with age, a majority of older people, even beyond age 75 , continue to rate their health as good or excellent $(57 \%)$. In the spinal cord injured population, Whiteneck and colleagues ${ }^{14}$ found that $77 \%$ of their sample of long-term survivors of spinal cord injury reported that they were in good health. McColl and Rosenthal ${ }^{24}$ also found $68 \%$ of a sample aged 45 years or older reporting good to excellent health.

Thus while our understanding of aging and mortality in spinal cord injury is evolving, precise estimates are still not available for expectations of life and health following a spinal cord injury. In order to derive these estimates, information about mortality and health must be combined into a single estimate. A number of efficient and informative methods are available for doing this: the health expectancy index or disability-free life expectancy index; ${ }^{2,25}$ the active life expectancy index; ${ }^{20}$ the QALY, or quality-adjusted life years, ${ }^{26}$ and the TWiST, or time without symptoms and toxicity. ${ }^{27}$ Each uses a different approach to estimate the number of years an individual of a certain age can expect to enjoy in various states of health, and each has different data requirements. In effect, all of these measures partition the remaining years of life into those that can typically be expected to be spent in good health and those spent in poor health.

Health expectancy estimates have been widely used in the literature of the last decade to try to understand the relationship between population health and survival, both in the general population and in several special populations. As an example of general population applications, Wilkins and Adams ${ }^{2}$ used information from the Canadian Mortality Data Base and the Canada Health Survey to demonstrate that in 1978, Canadian men might expect to live 70.8 years, 65.8 of which would be spent in good health; and Canadian women might expect to live 78.3 years, of which 71.7 years in good health.

Perhaps more interesting for our purposes are applications of the health expectancy approach to estimate expectations of health in special populations. An example is offered by Reynolds and colleagues. ${ }^{28}$ These researchers combined mortality information with information about activity limitations from the Health and Activity Limitations Survey. ${ }^{29}$ They showed that women with arthritis lost 3.3 years of healthy life expectancy, while men with arthritis lost 1.6 years of healthy life expectancy due to their disability. Health expectancy estimates have been used also to estimate the effects of dementia, ${ }^{30}$ cancer, ${ }^{31}$ hypertension $^{32}$ and other illnesses and medical interventions on aging populations.

The following study brings the benefit of this methodology to the question of long-term survival following spinal cord injury. Specifically, the study aims to: 
1 Calculate life and health expectancy in a population of spinal cord injured individuals.

2 Estimate the effect of factors associated with survival and health.

\section{Method}

\section{Design}

The study involved the synthesis of a retrospective cohort, all of whom sustained a spinal cord injury between 1945 and 1990. The cohort was followed over the 45 year period, to detect deaths. In addition, the cohort was surveyed in a cross-sectional fashion, to provide a prevalence estimate of the health of spinal cord injured individuals. While there are a number of different methods for estimating health expectancy, the simplest and most efficient is the prevalence life table method. ${ }^{25}$ This approach uses population mortality information in combination with sample survey information on prevalence of the conditions of interest, in this case, health.

\section{Subjects}

The subjects for the study are 606 individuals, all of whom had a truamatic spinal cord injury between January 11945 and December 31 1990; survived at least 1 year beyond the injury; and, received rehabilitation at either Lyndhurst Spinal Cord Centre in Toronto or Kingston General Hospital in Kingston between 1945 and 1991. In order to partially control for the known effects of age at injury on estimates of life and health expectancy, $8,10,11,14-16$ the cohort was restricted to those who experienced their injury at 25 to 34 years of age.

The cohort represents individuals who survived a traumatic spinal cord injury incurred between 25 and 34 years of age, southeastern and central Ontario during the period from 1945-1990. Given that virtually all people who incur and survive an acute spinal cord injury go on to receive rehabilitation, and given that both hospitals are regional rehabilitation centres, it may be assumed that by recruiting through the separation records of the two rehabilitation centres, all cases in the region over the period of time have been detected. Thus relatively complete capture of the cohort is assumed, with two notable exceptions. The cohort does not include those who sustained minimal or quickly resolving neurological impairment, and therefore did not receive rehabilitation. Neither does it include anyone who was ventilator dependent or who had a moderate to severe brain injury as well. Descriptive data on the cohort are presented in Table 1.

Of the original 606 cohort members, 142 were decreased at the time of the study. Attempts were made to contact by telephone all those who were believed to be alive $(n=464)$, to acquire survey information on healh. Of those, 334 were reached, and $130(28 \%)$ could not be located. Forty-eight $(10 \%)$ refused to participate and 286 were actually surveyed. Aggressive efforts were made to locate as many of the living subjects as possible, using hospital records from Lyndhurst, Kingston General or other hospitals listed in individual patient charts; admitting physician records; national telephone directories; next of kin; family physician records; records of other studies; records of the Canadian Paraplegic Association and Workers Compensation Board. Further, statistical analyses ( $t$-tests and Chisquare tests) showed no significant differences in the distributions of age, gender or level of injury between the 178 cohort members who did not participate and the 286 who did.

\section{Measurement}

1 The mortality information required for life and health expectancy calculations was obtained in several ways. At both hospitals, previous studies provided information about the majority of deaths in the cohort. ${ }^{1,3-5,33-36}$ Through the process of surveying, 12 additional deaths were discovered. Finally, for all those for whom mortality status was not known (that is, they were not known to be dead through previous research, nor were they known to be alive through contact for the survey), a record linkage was undertaken with Statistics Canada's Canadian Mortality Data Base. In this way, 23 additional individuals were identified who had died in Canada in the period between 1945 and 1990. Thus of the total of 606 individuals in the study, 142 had died by December 31 1991. The remainder of the cohort was assumed to be alive, although not all could be tracked at the time of the study. Since follow-up information was not available within the database, it was not possible to provide any additional information about last contact with those not reached by the telephone survey.

2 Survey information on health was collected by trained interviewers, one at each site (Kingston and Toronto), by means of a telephone survey. This efficient and cost-effective means of data collection resulted in high rates of compliance and return. Health was measured as self-rated health or perceived health on a ten-point scale. In spite of its simplicity, this approach to measuring health has been shown to be one of the most robust and valid measures of health available, as evidenced by correlations with other measures like morale, satisfaction and physician utilization. ${ }^{37}$

3 Demographic and injury-related data were abstracted from hospital records, and confirmed where possible using information from the survey. Demographic factors included: age at the time of the study; gender; occupation (professional/executive, semi-professional/managerial, sales/service, labour); marital status (married/common law, 
divorced/separated/widowed, single); employment (full-time, part-time, unemployed, retired). Injuryrelated variables included: age at time of injury, year of injury, level (paraplegia, quadriplegia) and completeness of injury (ASIA A, ASIA B-E). Both sets of variables have been found in previous research to be important predictors of health and survival among people with spinal cord injuries. $6,8,10,11,14-16$

\section{Results}

Life expectancy

Using the survival analysis procedure in SPSS (standard and Kaplan-Meier life tables), life expectancy was estimated for the cohort. Standard abridged life tables were produced, using 5 year intervals of time since injury as the basis for the tables. The 5 year intervals were chosen to ensure adequate cell frequencies for the health expectancy analysis to follow. These analyses invoke the assumption that mortality rates were stable over the 5 year time intervals, and the survival rates were similar over the 45 year period.

A summary life table based on 606 individuals, of whom 142 died, is shown in Table 2. Those individuals not identified as dead using the record linkage with Statistics Canada $(n=464)$ were considered alive (right-censored) at the time of the study. The censored cases may be assumed to be administrative censoring, rather than loss-to-follow-up; that is, they are known to be alive, rather than being lost-tofollow-up with mortality status unknown. The only deaths not captured by this method would be those which occurred to members of the cohort who no longer live in Canada. We expect that this number would be very small, since it is unlikely that many of the cohort would have forsaken access to the Canadian health care system as they grew older.

As shown in Table 3, 92\% of the sample were surviving at 10 years post-injury; $81 \%$ at 20 years; $63 \%$ at 30 years and $43 \%$ at 40 years post-injury. Although not shown in the table, the median survival time for the cohort is 37.9 years, meaning that $50 \%$ of the cohort lived about 38 years with their disability

Table 1 Demographic characteristics of the cohort and sample

\begin{tabular}{|c|c|c|c|}
\hline & $\begin{array}{l}\text { Total cohort } \\
\quad(\mathrm{n}=606)\end{array}$ & $\begin{array}{l}\text { Deceased } \\
(\mathrm{n}=142)\end{array}$ & $\begin{array}{c}\text { Survey } \\
(\mathrm{n}=286)\end{array}$ \\
\hline \multicolumn{4}{|l|}{ Age in 1990} \\
\hline $25-34$ & $133(21.9 \%)$ & $21(14.8)^{*}$ & $92(32.2)$ \\
\hline $35-44$ & $189(31.2)$ & $39(27.5)$ & $97(34.2)$ \\
\hline $45-54$ & $136(22.5)$ & $48(33.8)$ & $42(14.7)$ \\
\hline $55-64$ & $97(16.0)$ & $27(19.0)$ & $32(11.2)$ \\
\hline $65+$ & $51(8.4)$ & $7(4.9)$ & $22(7.7)$ \\
\hline means (s.d.) & $45.6(11.9)$ & $47.4(10.7)$ & $42.6(12.2)$ \\
\hline \multicolumn{4}{|l|}{ Gender } \\
\hline male & $518(85.5 \%)$ & $123(86.6 \%)$ & $249(87.1 \%)$ \\
\hline female & $88(14.5)$ & $19(13.40$ & 37 (12.9) \\
\hline \multicolumn{4}{|l|}{ Years since injury } \\
\hline $1-10$ & $236(38.9 \%)$ & $38(26.8 \%)$ & $152(53.1 \%)$ \\
\hline $11-20$ & $159(26.3)$ & $47(33.1)$ & $57(20.0)$ \\
\hline $21-30$ & $113(18.6)$ & $40(28.1)$ & $40(14.0)$ \\
\hline $31-40$ & $86(14.2)$ & $16(11.3)$ & $29(10.1)$ \\
\hline $41+$ & $12(2.0)$ & $1(0.7)$ & $8(2.8)$ \\
\hline means (s.d.) & $16.5(11.6)$ & $20.4(12.8)$ & $13.8(11.7)$ \\
\hline \multicolumn{4}{|l|}{ Years of injury } \\
\hline $1945-50$ & $42(6.9)$ & $26(18.3 \%)$ & $9(3.1)$ \\
\hline $1951-60$ & $129(21.3)$ & $61(43.0)$ & $29(10.2)$ \\
\hline $1961-70$ & $111(18.3)$ & $32(22.5)$ & $43(15.0)$ \\
\hline $1971-80$ & $132(21.8)$ & $18(12.7)$ & $60(21.0)$ \\
\hline $1981-90$ & $182(31.7)$ & $5(3.5)$ & $145(50.7)$ \\
\hline means (s.d.) & $1970(13.1)$ & $1959(10.1)$ & $1976(11.7)$ \\
\hline \multicolumn{4}{|l|}{ Nature of injury } \\
\hline complete para & $164(27.1 \%)$ & $46(32.4)$ & $78(27.4 \%)$ \\
\hline incomplete para & $173(28.5)$ & $31(21.8)$ & $64(22.4)$ \\
\hline complete tetra & $120(19.8)$ & $39(27.5)$ & $69(24.2)$ \\
\hline incomplete tetra & $148(24.4)$ & $26(18.3)$ & $74(25.9)$ \\
\hline
\end{tabular}


(calculated using the Kaplan-Meier life table with 1 year intervals). The $95 \%$ confidence interval for the median survival estimate is $33.5-40.5$ years. These estimates are somewhat difficult to interpret, since they require the assumption that survival experience is similar across the cohort and over the period of study. We know from previous research that this is not the case; that factors like age and time of injury, level and completeness of lesion all affect survival. Thus at best, these overall estimates of survival for the cohort are crude summary estimates for the population.

Using a hypothetical population of 100000 individuals, and using rates estimated from the cohort, life expectancy was estimated at each interval (see Table 3). The life table was closed out by assuming that the conditional probability of dying in the last interval $(45+$ years since injury) was 1.0 , and 5 remaining life-years were attributed to each individual entering the final interval. The estimate of 5 years was based on the fact that the three individuals actually found in the last interval were right-censored cases, therefore their remaining duration of life is unknown. The estimate of 5 additional years lived is a conservative one, which may have resulted in slightly conservative overall estimates of life expectancy. The life table implies that the mean age at death increased steadily with each interval survived, to a maximum of about 78 years for those living 40 or more years postinjury (average age at injury $30+40$ years postinjury +8.7 remaining years life expectancy $=78.7$ years).

Table 4 provides some hypothetical applications of the information derived from the life table. It shows that whereas at the onset of disability, an individual who survived the first year post-injury could expect to live a total of $34-35$ years with his or her disability, at 30 years post-injury, an individual could expect to spend a total of 44 or 45 years with a disability. Further, if we take the example of someone injured at 30 years of age, at onset he or she would expect to live to about 65 years of age, whereas at 40 years post injury, he or she would expect to live to about 78 years
Table 2 Standard abridged life table for spinal cord injured cohort (Kaplan-Meier method) $(n=606)$

\begin{tabular}{lrrrc}
\hline$x$ & $l_{x}$ & $W_{x}$ & $d_{x}$ & $s(x)(\operatorname{se} s(x))$ \\
\hline $0-4$ & 606 & 89 & 15 & $0.9743(0.007)$ \\
$5-9$ & 502 & 98 & 22 & $0.9281(0.012)$ \\
$10-14$ & 382 & 60 & 20 & $0.8750(0.016)$ \\
$15-19$ & 302 & 54 & 19 & $0.8147(0.020)$ \\
$20-24$ & 229 & 38 & 31 & $0.6958(0.026)$ \\
$25-29$ & 160 & 41 & 12 & $0.6382(0.029)$ \\
$30-34$ & 107 & 37 & 13 & $0.5491(0.034)$ \\
$35-39$ & 57 & 31 & 8 & $0.4366(0.046)$ \\
$40-44$ & 18 & 13 & 2 & $0.3608(0.065)$ \\
$45+$ & 3 & 3 & 0 & $0.0000^{*}$ \\
\hline
\end{tabular}

where: $\mathrm{x}=$ years since injury; $1_{\mathrm{x}}=$ number entering the interval; $\mathrm{W}_{\mathrm{x}}=$ number withdrawn/censored from the interval; $d_{x}=$ number dying within the interval; $s(x)=$ cumulative probability of survival to the end of the interval; $\operatorname{se}(\mathrm{s}(\mathrm{x}))=$ standard error of survival rate. *hypothetical value
Table 4 Applications of life expectancy information to spinal cord injured cohort

\begin{tabular}{|c|c|c|c|c|c|}
\hline$X$ & $e_{x}$ & $L E_{x}$ & Total $L E_{x}$ & $\begin{array}{l}\text { Increase } \\
\text { in } L E_{x} \\
(\%)\end{array}$ & $\begin{array}{l}\text { Increase } \\
\text { in LE } E_{x} \\
\text { (net yrs.) }\end{array}$ \\
\hline $0-4$ & 34.65 & 34.65 & 64.65 & - & - \\
\hline $5-9$ & 30.53 & 35.53 & 65.53 & 1.013 & 0.88 \\
\hline $10-14$ & 29.96 & 36.96 & 66.96 & 1.022 & 1.43 \\
\hline $15-19$ & 23.43 & 38.43 & 68.43 & 1.022 & 1.47 \\
\hline $20-24$ & 19.99 & 39.99 & 69.99 & 1.023 & 1.56 \\
\hline $25-29$ & 18.02 & 43.02 & 73.02 & 1.043 & 3.03 \\
\hline $30-34$ & 14.48 & 44.48 & 74.48 & 1.020 & 1.46 \\
\hline $35-39$ & 11.54 & 46.54 & 76.54 & 1.028 & 2.06 \\
\hline $40-44$ & 8.70 & 48.70 & 78.70 & 1.028 & 2.16 \\
\hline $45+$ & 5.00 & 50.00 & 80.00 & 1.016 & 1.30 \\
\hline
\end{tabular}

where: $x=$ years since injury: $e_{x}=$ expectation of life beyond the interval; $\mathrm{LE}_{\mathrm{x}}=$ expectation of life with a disability; Total $\mathrm{LE}_{\mathrm{X}}=$ total expectation of life, assuming age 30 at injury

Table 3 Life expectancy based on estimates from spinal cord injured cohort** (life table method)

\begin{tabular}{|c|c|c|c|c|c|c|}
\hline$x$ & $l_{x}$ & $q_{x}$ & $d_{x}$ & $L_{x}$ & $T_{x}$ & $e_{x}$ \\
\hline $0-4$ & 100000 & 0.0267 & 2670 & 493325 & 3464671 & 34.65 \\
\hline $5-9$ & 97330 & 0.0486 & 4730 & 474824 & 2971346 & 30.53 \\
\hline $15-19$ & 87340 & 0.0691 & 6035 & 421612 & 2046672 & 23.43 \\
\hline $20-24$ & 81305 & 0.1476 & 12001 & 376523 & 1625059 & 19.99 \\
\hline $25-29$ & 69304 & 0.0860 & 5960 & 331621 & 1248536 & 18.02 \\
\hline $35-39$ & 54039 & 0.1928 & 10419 & 244148 & 623458 & 11.54 \\
\hline $40-44$ & 43620 & 0.1739 & 7586 & 199137 & 379310 & 8.70 \\
\hline $45+$ & 36035 & $1.000 *$ & 36035 & 180173 & 180173 & 5.00 \\
\hline
\end{tabular}

where: $x=$ years since injury: $1_{x}=$ number entering the interval; $q_{x}=$ proportion dying in the interval; $d_{x}=$ number dying within the interval; $\mathrm{L}_{\mathrm{x}}=$ number of person-years in the interval; $\mathrm{T}_{\mathrm{x}}=$ number of person-years in total; $\mathrm{e}_{\mathrm{x}}=$ expectation of life at start of interval. **rates computed on cohort $(n=606)$ injured between ages 25 and 34 . *hypothetical rate 
of age. Thus for each decade lived post-injury, a net increase in expected mean age at death was experienced: 2.3 years for the first decade, 3 years for the second decade, and about 4.5 years each for the next two decades.

Figure 1 shows the survival function for the cohort from injury onset to 45 years. The survival function plots the cumulative probability of surviving to the end of each interval. The survival function for the present cohort shows an almost linear decline in survival over time. Most notably, it lacks the usual plateau found at the early stages of most plots of general population survival, and instead reveals deaths occurring at almost steady intervals across the time period.

\section{Expectations of health}

On a self-report scale of perceived health, measured from $1-10,22.7 \%$ of the total sample reported health below the mid-point of the scale $(1-5)$, or in the range

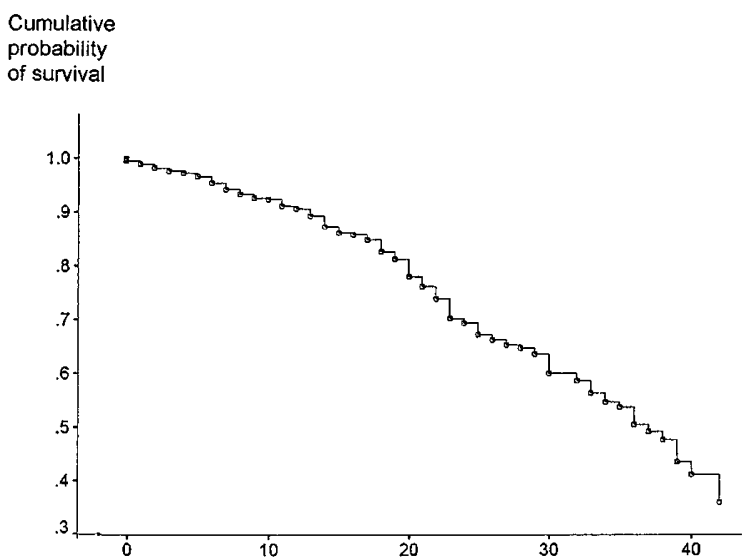

Figure 1 Survival curve for spinal cord injured cohort generally considered fair to poor. ${ }^{37}$ Sixty-two percent reported good health $(6-8)$, and $14.7 \%$ reported excellent health $(9$ or 10$)$. The distribution of health for survey respondents is shown in Table 5.

Expectations of health for the cohort were estimated using the health expectancy approach. The abridged life table was again used, with 10 year intervals of time since injury as the basis for the table. Health prevalence estimates from the survey were used to estimate the proportion of total life years spent by the cohort in good $v s$ poor health. The prevalence approach to estimating expectations of health makes no assumptions about the direction of transitions from good to poor health or vice versa. Neither does it offer a longitudinal perspective on the actual experience of the cohort as regards transitions to different health states and ultimately to death. Instead, it offers a 'snapshot' of the actual amounts of time spent by individuals at different times post-injury in different states of health and illness.

Table 5 shows the proportions of the survey sample $(n=286)$ in each state of health for each decade post-injury, the expectations of life and expectations of health by decade post-injury. Expectations of health are shown both as actual years and as proportions of the total life expectancy at each interval. The table shows a relatively constant expectation of about 5-7 remaining years of poor health. However, on closer examination, the expectation of remaining years spent in poor health dropped slightly with increasing time post-injury, with those at injury expecting about 2 more years of poor health than those at 40 years post-injury (7.2 vs 5.2 years). This was accompanied by a steadily decreasing period of good health as the years go by, from 27 years down to 3 years. Up to 40 years post-injury, the remaining years expected to be spent in good health exceeded the years in poor health. However, for those 40 or more years post-injury, the expected years remaining in poor health exceeded the expected years remaining in good health. While the proportion of

Table 5 Expectations of life and health for spinal cord injured cohort*

\begin{tabular}{|c|c|c|c|c|c|c|}
\hline \multirow[b]{3}{*}{$x$} & \multirow{2}{*}{\multicolumn{2}{|c|}{ Life expectancy }} & \multicolumn{2}{|c|}{ Health expectancy } & \multirow{2}{*}{\multicolumn{2}{|c|}{ Colf nat holth }} \\
\hline & & & Good health & Poor health & & \\
\hline & Survivors & Total & $(\%)$ & $(\%)$ & Good health & Poor health \\
\hline $0-9$ & 100000 & 34.65 & $\begin{array}{c}27.5 \\
(793)\end{array}$ & $\begin{array}{c}7.2 \\
0.7)\end{array}$ & 0.924 & 0.076 \\
\hline $10-19$ & 92600 & 26.96 & $\begin{array}{c}20.0 \\
(74.2)\end{array}$ & $\begin{array}{c}7.0 \\
(25.8)\end{array}$ & 0.867 & 0.133 \\
\hline $20-29$ & 81305 & 19.99 & $\begin{array}{c}13.5 \\
(67.5)\end{array}$ & $\begin{array}{c}6.5 \\
(32.5)\end{array}$ & 0.837 & 0.163 \\
\hline $30-39$ & 63334 & 14.48 & $\begin{array}{c}7.7 \\
(53.1)\end{array}$ & $\begin{array}{c}6.5 \\
(46.9)\end{array}$ & 0.655 & 0.345 \\
\hline $40+$ & 43620 & 8.70 & $\begin{array}{c}3.5 \\
(40.0)\end{array}$ & $\begin{array}{c}5.2 \\
(60.0)\end{array}$ & 0.400 & 0.600 \\
\hline
\end{tabular}

where: $\mathrm{x}=$ time since injury: *calculations based on prevalance rates from survey sample $(n=286)$ and survival rates for full cohort $(n=606)$ 
remaining life-years spent in good health declined from $80-40 \%$, the proportion spent in poor health increased correspondingly from $20-60 \%$.

\section{Factors affecting survival}

Cox proportional hazards regression was used to determine multivariate estimates of the risk associated with five factors identified in previous research as potentially influential on survival: gender, year of injury, level of lesion, completeness of injury, age at injury. ${ }^{14,15,17-19}$ The Cox proportional hazards approach was chosen for the present analysis because it offers a way of dealing with censored cases, or those cases for whom no event (death) occurs before the end of the study. Thus estimates of factors associated with survival are not biased by excluding from the analysis those cases who have not experienced the event, and who may have the longest survival. Other advantages of this approach include the fact that it allows simultaneous consideration of a number of predictors; inclusion of both continuous and categorical variables; and, estimation of main and interaction effects of covariates. $^{38,39}$ The proportional hazards assumption, that the ratio of the hazard rates remains constant over time, was tested using the ' $\log (-\log )$ ' plot for each of the factors studied. Since the plots associated with each stratum of the factors were approximately parallel, the proportional hazards assumption was upheld.

Hierarchical block regression was used to test the model, entering first gender, as it is known to affect survival in the general population. Second, the two injury-related variables, level and completeness of lesion, were entered. Finally, the year of injury and age at injury were entered. This analysis resulted in an overall model that was significant $(P<0.0001)$, with three significant variables: level of lesion, completeness of lesion and age at injury $(-2 \mathrm{LL}=1486.4$; Chisquare, 3 d.f. $=27.05$ ).

A significant effect was found for the level of lesion $(\mathrm{RR}=1.66 ; 95 \% \mathrm{CI}=1.18-2.33)$. Those with quadriplegia were about one and half times as likely to die at any given point throughout the survival period as those with paraplegia. Completeness of lesion also appeared to be a significant predictor of survival $(\mathrm{RR}=1.97 ; 95 \% \mathrm{CI}=1.40-2.78)$. Thus those with a complete lesion experienced a two-fold increase in the risk of death over those with an incomplete lesion. Age at injury, ranging from 25 to 34 years in this study, was also a significant predictor of survival $(\mathrm{RR}=1.07 ; 95 \% \mathrm{CI}=1.01-1.14)$. For each additional year lived before the injury, a $7 \%$ increase accrued in the risk of death.

Gender and year of injury both had risk ratios whose $95 \%$ confidence interval included the value 1 , suggesting that the true risk associated with either factor was not significantly different from 1 .

Stratified survival analyses were then undertaken, comparing survival functions at two levels of each of the significant factors: level and completeness of lesion. There were significant differences in the survival probabilities for paraplegics $v s$ quadriplegics (log-rank test; Chi-square $=7.16,1$ d.f., $P=0.007)$, and in the median survival times (41 years post injury with paraplegia, v 32 years post-injury with quadriplegia). While almost $50 \%$ of paraplegics survived beyond 40 years post-injury, only about $15 \%$ of quadriplegics could expect the same.

There were also significant differences in survival post-injury between those with complete vs incomplete lesions (Chi-square $=15.88,1$ d.f., $P<0.001$ ). Approximately 10 years difference existed between the median survival times of those with incomplete lesions (41.4 years) and those with complete lesions (31.6 years). Thus while $31 \%$ of those with complete lesions could expect to survive at least 35 years postinjury, $54 \%$ of those with complete lesions could expect the same.

No significant difference was found between the post-injury survival rates of men $v s$ women. A median survival time of 42 years was found for the women in the sample, and 37 years for the men. This represents a difference in survival between men and women of about 5 years, slightly less than the 6 years difference found in recent general population analyses. ${ }^{29}$ However, these estimates must be treated with caution because of the large standard errors and wide confidence intervals, especially around the estimate for females. The relatively small number of women in the cohort makes it difficult to generate precise estimates of their survival.

Table 7 gives average life expectancies for those with paraplegia and those with quadriplegia, as well as those with complete and incomplete lesions. The average life expectancy beyond injury for those with paraplegia appears to be $4-6$ years longer than those with quadriplegia, with this difference diminishing slightly as time goes on. At onset, those with incomplete lesions have a life expectancy of almost 8 more years compared to those with complete lesions, and about 3 more years at 40 years post injury. Again, the effects of this variable appear to attenuate with increasing time since injury.

Table 8 provides information about the expectations of health for the same four subgroups of the cohort. It shows expectations of poor health being roughly similar regardless of the level of injury:

Table 6 Factors affecting survival for spinal cord injured cohort $(n=606)$

\begin{tabular}{lccccc}
\hline Predictors & $B$ & conf limit & $\exp (B)$ & $\begin{array}{c}\text { Upper } \\
\text { conf limit }\end{array}$ & $P$ \\
\hline $\begin{array}{c}\text { Level of } \\
\text { lesion }\end{array}$ & 0.6798 & 1.4019 & 1.9736 & 2.7786 & 0.000 \\
$\begin{array}{c}\text { Complete } \\
\text { lesion }\end{array}$ & 0.5077 & 1.1831 & 1.6615 & 2.3333 & 0.003 \\
$\begin{array}{c}\text { Age at } \\
\text { injury }\end{array}$ & 0.0689 & 1.0051 & 1.0713 & 1.1419 & 0.034 \\
\hline
\end{tabular}


about 9 years for those with paraplegia and 8 years for those with quadriplegia. By contrast, those with complete and incomplete lesions have very different expectations of ill health: 14 and 5 years respectively.

Factors affecting self-rated health

To explore factors associated with health, multiple regression analyses were conducted, regressing selfrated health against the following covariates: age, gender, level of lesion, completeness of injury, year of injury, duration of disability, employment, occupation and marital status. Hierarchical block regression was used, proceeding in the following manner. The basic demographic variables, age and gender, were entered first; injury-related variables, level and completeness, were entered second; duration of disability was entered third; year of injury was entered fourth; and finally, the three social status variables, marital status, occupation and employment, were entered last

Table 7 Expectations of life for those with paraplegia $v s$ quadriplegia and those with complete $v s$ incomplete lesions $v s$ quadriplegia $\left(n_{\mathrm{q}}=268\right)$

\begin{tabular}{|c|c|c|c|c|c|c|c|}
\hline \multirow[b]{2}{*}{$x$} & \multirow[b]{2}{*}{ Total } & \multicolumn{3}{|c|}{ Level of lesion } & \multicolumn{3}{|c|}{ Completeness of lesion } \\
\hline & & Para & Quad & Difference & Incomplete & Complete & Difference \\
\hline $0-4$ & 34.65 & 36.75 & 30.12 & 6.63 & 37.63 & 29.84 & 7.79 \\
\hline $5-9$ & 30.53 & 32.30 & 26.29 & 6.01 & 33.23 & 25.92 & 7.31 \\
\hline $10-14$ & 26.96 & 28.84 & 22.50 & 6.34 & 28.62 & 23.23 & 5.39 \\
\hline $15-19$ & 23.43 & 25.25 & 18.93 & 6.32 & 25.06 & 19.61 & 5.45 \\
\hline $20-24$ & 19.99 & 21.47 & 15.79 & 5.68 & 21.35 & 16.25 & 5.10 \\
\hline $25-29$ & 18.02 & 19.26 & 13.85 & 5.39 & 18.72 & 14.52 & 4.20 \\
\hline $30-34$ & 14.48 & 15.94 & 9.76 & 5.18 & 14.76 & 11.22 & 3.54 \\
\hline $35-39$ & 11.54 & 12.32 & 7.75 & 4.57 & 11.55 & 8.13 & 3.42 \\
\hline $40-44$ & 8.70 & 9.17 & 5.00 & 4.17 & 8.24 & 5.00 & 3.24 \\
\hline $45+$ & 5.00 & 5.00 & - & 5.00 & 5.00 & - & 5.00 \\
\hline
\end{tabular}

where: $\mathrm{x}=$ years since injury. *rates computed on sample injured between ages 25 and 34

Table 8a Expectations of health for those with paraplegia vs. quadriplegia

\begin{tabular}{|c|c|c|c|c|c|c|c|}
\hline$x$ & Total & Total & $\begin{array}{l}\text { Paraplegia } \\
\text { Good health }\end{array}$ & Poor health & Total & $\begin{array}{l}\text { Quadriplegia } \\
\text { Good health }\end{array}$ & Poor health \\
\hline $0-4$ & 34.65 & 36.75 & $\begin{array}{l}26.78 \\
(72.9)\end{array}$ & $\begin{array}{c}9.96 \\
(26.1)\end{array}$ & 30.12 & $\begin{array}{l}21.73 \\
(72.1)\end{array}$ & $\begin{array}{c}8.39 \\
(27.9)\end{array}$ \\
\hline $0-14$ & 26.96 & 28.84 & $\begin{array}{l}19.14 \\
(66.4)\end{array}$ & $\begin{array}{l}9.70 \\
(35.6)\end{array}$ & 22.50 & $\begin{array}{l}13.97 \\
(62.1)\end{array}$ & $\begin{array}{c}8.53 \\
(37.9)\end{array}$ \\
\hline $20-24$ & 19.99 & 21.47 & $\begin{array}{l}11.58 \\
(53.9)\end{array}$ & $\begin{array}{l}9.89 \\
(46.1)\end{array}$ & 15.79 & $\begin{array}{c}7.51 \\
(34.5)\end{array}$ & $\begin{array}{l}8.28 \\
(65.5)\end{array}$ \\
\hline $30-34$ & 14.48 & 15.94 & $\begin{array}{c}5.69 \\
(35.7)\end{array}$ & $\begin{array}{l}10.25 \\
(54.3)\end{array}$ & 9.76 & $\begin{array}{c}0.00 \\
(0.00)\end{array}$ & $\begin{array}{l}9.76 \\
(100)\end{array}$ \\
\hline $40-44$ & 8.70 & 9.17 & $\begin{array}{c}0.00 \\
(0.00)\end{array}$ & $\begin{array}{l}9.17 \\
(100)\end{array}$ & 5.00 & $\begin{array}{c}0.00 \\
(0.00)\end{array}$ & $\begin{array}{l}5.00 \\
(100)\end{array}$ \\
\hline
\end{tabular}

Table 8b Expectations of health for those with complete $v s$ incomplete lesions

\begin{tabular}{|c|c|c|c|c|c|c|c|}
\hline$x$ & Total & Total & $\begin{array}{l}\text { Incomplete } \\
\text { Good health }\end{array}$ & Poor health & Total & $\begin{array}{c}\text { Complete } \\
\text { Good health }\end{array}$ & Poor health \\
\hline $0-4$ & 34.65 & 37.63 & $\begin{array}{l}24.27 \\
(64.5)\end{array}$ & $\begin{array}{c}5.58 \\
(35.5)\end{array}$ & 29.84 & $\begin{array}{l}23.20 \\
(77.7)\end{array}$ & $\begin{array}{l}14.43 \\
(22.3)\end{array}$ \\
\hline $0-14$ & 26.96 & 28.62 & $\begin{array}{l}17.99 \\
(62.6)\end{array}$ & $\begin{array}{c}5.24 \\
(37.4)\end{array}$ & 23.23 & $\begin{array}{l}14.20 \\
(61.1)\end{array}$ & $\begin{array}{l}14.42 \\
(38.9)\end{array}$ \\
\hline $20-24$ & 19.99 & 21.35 & $\begin{array}{l}11.86 \\
(55.6)\end{array}$ & $\begin{array}{c}4.38 \\
(44.4)\end{array}$ & 16.25 & $\begin{array}{c}6.52 \\
(40.1)\end{array}$ & $\begin{array}{l}14.84 \\
(59.9)\end{array}$ \\
\hline $30-34$ & 14.48 & 14.76 & $\begin{array}{c}5.97 \\
(40.4)\end{array}$ & $\begin{array}{c}5.25 \\
(59.6)\end{array}$ & 11.22 & $\begin{array}{c}0.00 \\
(0.001)\end{array}$ & $\begin{array}{l}14.76 \\
(100)\end{array}$ \\
\hline $40-44$ & 8.70 & 8.24 & $\begin{array}{c}0.00 \\
(0.00)\end{array}$ & $\begin{array}{c}5.00 \\
(100)\end{array}$ & 5.00 & $\begin{array}{c}0.00 \\
(0.00)\end{array}$ & $\begin{array}{c}8.24 \\
(100)\end{array}$ \\
\hline
\end{tabular}

where: $\mathrm{x}=$ years since injury. *rates computed on sample injured between ages 25 and 34 
Table 9 Factors affecting health for sample of spinal cord injured individuals $(n=286)$

\begin{tabular}{lrlrc}
\hline $\begin{array}{l}\text { Predictors } \\
\text { of health }\end{array}$ & $B$ & se $(B)$ & $T$ & $P$ \\
\hline Age & -0.036 & 0.0087 & -4.18 & 0.000 \\
Employment & 0.835 & 0.256 & 3.26 & 0.001 \\
Occupation & -0.204 & 0.70 & -2.90 & 0.004 \\
\hline
\end{tabular}

Adjusted $\mathrm{R}^{2}=0.177 \mathrm{~F}(3,281)=21.39 P<0.001$

(as dummy variables), to assess if any improvement of fit was achieved by accounting for these factors. Only the 286 individuals for whom survey information was available were used in this analysis.

The final model for self-rated health contained three variables, and explained $17.7 \%$ of the variance in health status as a result of age, occupation and employment $(\mathrm{F}(3,281)=21.39 ; P<0.001)$. As age increased, reported health status deteriorated $(\mathrm{B}=-0.036 ; P<0.001)$. Those who were employed reported significantly better health $(B=0.835$; $P<0.001)$, and those whose occupations were typically more financially rewarding and higher status (e.g., professional, management, business) reported better health $(\mathrm{B}=-0.204 ; P<0.005)$.

\section{Discussion}

To summarize, the study set out to discover expectations of life and health in a population of spinal cord injured individuals. The study offers information about survival, factors affecting survival and health over their expected lifetime for individuals who incurred a traumatic spinal cord injury at ages 25-34 years, from 1945-1990, in central and southeastern Ontario.

The study predicts a median survival of 38 years post-injury, with $43 \%$ surviving at least 40 years postinjury. These estimates compare favourably with those generated by Whiteneck and colleagues, ${ }^{14}$ who found median survival to be 32 years, with $35 \%$ surviving at least 40 years. In fact, there appears to be about an $8-$ $10 \%$ margin of increased survival in the present study. However, Whiteneck's sample differed in a significant way from ours: it included only those individuals who had their injury at least 20 years, thereby excluding individuals injured between 1970 and 1990. In our study, these individuals contributed only about $10 \%$ of the deaths, and therefore probably had a net effect of increasing life expectancy.

Samsa and colleagues ${ }^{15}$ estimated mean survival beyond spinal cord injury at 39 years in their sample of spinal cord injured veterans. While their sample is similar to ours on some age and injury characteristics, they included those injured at any age $(17-39$ years of age), those injured only after 1967 , and all were men and members of the armed forces. While our results, as well as general population findings about life expectancy, show that men's life expectancy is less than women's, Samsa's own findings from the control samples shows that military affiliation has a positive effect on survival. Samsa's study also provides an interesting comparison for the survival curve found in Figure 1 , in that it shows the same steady decline in the curve, or in the cumulative probability of survival, over the period.

Although detailed comparisons between samples are problematic, because of differences in sampling procedures, if we look in the most general sense at the results of this and other recent studies, the findings are very similar. Taking 30 as the average age at injury, and disregarding the effects of level and completeness for the moment, we found a median life expectancy of 38 years post injury, suggesting a total life expectancy of about 68 years. Comparing this with Geisler's work about a decade earlier, ${ }^{1}$ those injured at 30 years of age expected $32-37$ remaining years of life (except for complete quadriplegics, 23 years), for an overall expected age at death of about 64.5 years. Thus it seems there has been a slight improvement in overall life expectancy, regardless of level or completeness of lesion. In Whiteneck's study, those injured at 30 years or less expected 36-44 years more, depending on level and completeness (excluding those with complete quadriplegia), for a total life expectancy of $66-74$ years. These findings too suggest an increase in life expectancy of about 5 years over Geisler's 1983 study.

Factors affecting survival in the present study were age at injury, level and completeness of lesion. In spite of having restricted age at injury to a 10 year interval, we found that for each individual year lived before the injury, there was a 7\% increase in the risk of death. This finding is consistent with those of several other studies, all of which agree that injury at a younger age offers the opportunity for better long-term outcomes. ${ }^{11,14,15,40}$ Whiteneck and colleagues ${ }^{14}$ found a 2.7 times increase in the odds of death for those injured between 30-40 years of age, compared to those injured before 30 .

Not surprisingly, level and completeness of lesion were also significant predictors of survival. Of all the literature reviewed, only Samsa and colleagues ${ }^{15}$ did not find this to be the case, suggesting that the effects of injury severity were less pronounced in studies of medium to long-term survival. While our findings support the idea that injury-related variables become less influential on survival outcomes with increasing time since injury, we continued to find a significant effect of both variables up to 40 years post-injury.

Those with quadriplegia had a risk of death 1.7 times greater than those with paraplegia, resulting in a median survival time for paraplegic individuals of about 9 years greater than that for those who were quadriplegic (41 years post-injury vs 32 years). This finding is consistent with most other studies. Whiteneck and colleagues ${ }^{14}$ found an odds ratio of 1.4 for those with quadriplegia over those with paraplegia. Geisler and associates ${ }^{1}$ found that those who were 
paraplegic had 5-12 years more of life than those who were quadriplegic, depending on the completeness of their lesion. Whiteneck and associates ${ }^{14}$ also found that paraplegic individuals lived 2-8 years longer than those who were quadriplegic, depending on completeness of lesion and age at injury.

Similarly, completeness of lesion was also found in other studies to have a significant effect on life expectancy. The relative risk found in our study of almost two for those with complete lesions over those with incomplete is again slightly higher than the odds of 1.5 found by Whiteneck. ${ }^{14}$ Thus, comparing the present study with Geisler and colleagues ${ }^{1}$ and with Whiteneck and associates, ${ }^{14}$ one finds that in spite of differences in samples and procedures, the three studies produce fairly similar estimates of survival post-injury for individuals injured at about 30 years of age, with the expectation of life appearing to improve slightly in the decade since Geisler's study.

As regards expectations of health, estimates found in the present study are similar to those found in studies of the general population in Canada over a similar period. ${ }^{2}$ Both show a fairly similar period of poor health, 5-7 years in this study. Longitudinal research on aging and spinal cord injury shows that while life satisfaction remains fairly constant over a 3 year follow-up period, health indicators deteriorate. ${ }^{41}$ The British cohort showed increased prevalence of musculo-skeletal complaints, pressure sores, cardiac and circulatory problems, bowel and bladder complications and fatigue. These findings support our assumption of deteriorating health with increasing time since injury (as well as advancing age), and lead us to conclude that the 5-7 years of poor health reported by our respondents are probably experienced near the end of their lives. This pattern supports the more optimistic view of healthy life expectancy discussed earlier, ${ }^{21,22}$ where morbidity continues to be compressed into the last few years of life, and increases in life expectancy are largely accounted for by increases in years of healthy life.

In fact, as mentioned earlier, the total expectation of poor health post-injury decreases in absolute terms from 7-5 years as the time since onset of injury increases from $0-40$ years. This is probably accounted for by the 'healthy survivor' phenomenon, where those who survive to the latter intervals are generally healthier throughout the lifespan, and have more years of healthy life expectancy.

The study has a number of both methodological and substantive limitations which must be accounted for in the interpretation of the results. In terms of substantive limitations, the nature of the sample restricts the inferences that can be drawn from the present study. First, the sample of 606 is relatively small for analyses of this kind. This is somewhat inevitable in working with a very specialized population; however, it may be possible in future studies to augment the sample size by enlisting the participation of other spinal cord rehabilitation centres. Second, only traumatically injured individuals are considered in the sample, because of the need for a known date of onset for the calculation of time since injury, and for comparability with other mortality studies in this population. Third, only individuals who have survived 1 year after injury are considered here. Therefore, generalizations of this work cannot include those individuals who did not survive to reach the rehabilitation centre or beyond 1 year. Fourth, the sample was restricted to those injured between 25 and 34 years, in an attempt to control for age at injury. Fifth, because of admission criteria at the rehabilitation centres where the sample was recruited, the sample would not include those who were ventilator dependent, or those with a moderate to severe brain injury.

On the positive side, the sample represents all discharges from the two rehabilitation centres concerned. These two centres cover a geographic area in central and southeastern Ontario, with a total population of about 4.5 million people. This region was exclusively served by one or both of the two rehabilitation centres since 1945, and because of the jurisdiction of health services and legislated patterns of transportation for trauma, we have some assurances that the cohort represents the entire population within the identified region. Further, we are confident of the accurate detection of death within the population, because of the link with national mortality statistics.

Methodologically, the manner in which the life tables were closed out is relatively speculative, due to right censoring of the longest surviving cases. Thus, as discussed earlier, the tables generated are expected to underestimate true survival.

Finally, the health expectancy method used here ${ }^{25}$ does not produce an integrated longitudinal view of the actual mortality and morbidity experience of a cohort. Instead, it produces a cross-sectional view of states of health, independence and quality of life for the surviving members of a population. Future research taking a longitudinal approach would allow us to better understand the actual aging experiences of individuals and groups within the population, and the relationships between their health and survival.

\section{Acknowledgements}

The authors gratefully acknowledge the financial support of the Man in Motion Legacy Fund. Thanks too to Lyndhurst Hospital for use of the Lyndhurst Mortality Data Base, and to Statistics Canada for use of the Canadian Mortality Data Base. Finally, our thanks to the survey participants and interviewers.

\section{References}

1 Geisler WO, Jousse AT, Wynne-Jones M. Survival in traumatic cord injury. Paraplegia 1983; 21: $364-373$. 
2 Wilkins R, Adams OB. Health expectancy in Canada, late 1970: Demographic, regional and social dimensions. American Journal of Public Health 1983; 9: 1073 - 1080,

3 Breithaupt DJ, Jousse AT, Wynne-Jones M. Late causes of death and life expectancy in paraplegia. The Canadian Medical Association Journal 1961; 85: 73 - 77.

4 Jousse AT, Wynne-Jones M, Breithaupt DJ. A follow-up of life expectancy and mortality in traumatic transverse myelitis. The Canadian Medical Association Journal 1968; 98: 770 - 772.

5 Geisler WO, Jousse AT, Wynne-Jones M. Survival in traumatic transverse myelitis. Paraplegia 1977; 14: $262-275$.

6 DeVivo MJ et al. Seven-year survival following spinal cord injury. Arch Neurol 1987; 44: $872-875$.

7 DeVivo MJ, Black KJ, Richards JS, Stover SL. Suicide following spinal cord injury. Paraplegia 1991; 29: 620-627.

8 DeVivo MJ, Stover SL, Black KJ. Prognostic factors for 12-year survival after spinal cord injury. Arch Phys Med Rehabil 1992; 73: $156-162$.

9 Krause JS, Franti CE, Borhani NO, Riggins RS. Survival with an acute spinal cord injury. Journal of Chronic Diseases 1979; 32: $269-283$.

10 Krause J. Survival following spinal cord injury: A fifteen year prospective study. Rehabilitation Psychology 1991; 36: 89-97.

11 Krause JS, Crewe NM. Prediction of long-term survival of persons with spinal cord injury: An 11-year prospective study. Rehabilitation Psychology 1987; 32: 205 - 211.

12 Krause JS, Kjorsvig JM. Mortality after spinal cord injury: A four-year prospective study. Arch Phys Med Rehabil 1992; 73: $558-563$.

13 Lammertse DP, Yarkony GM. Rehabilitation in spinal cord disorders. 4. Outcomes and issues of aging after spinal cord injury. Arch Phys Med Rehabil 1991; 72: S309-S311.

14 Whiteneck $G$ et al. Mortality, morbidity and psychosocial outcomes of persons with spinal cord injury injured more than twenty years ago. Paraplegia 1992; 30: 617-630.

15 Samsa GP, Patrick CH, Feussner JR. Long-term survival of veterans with traumatic spinal cord injury. Arch Neurol 1993; 50: $909-914$.

16 Hackler RH. A 25-year prospective mortality study in the spinal cord injured patient: Comparison with the long-term living paraplegic. Journal of Urology 1977; 117: 486-488.

17 Kiwerski JE. Factors contributing to the increased threat to life following spinal cord injury. Paraplegia 1993; 31: $793-799$.

18 DeVivo MJ, Black KJ, Stover SL. Causes of death during the first 12 years after spinal cord injury. Archives of Physical Medicine and Rehabilitation 1993; 74: $248-254$.

19 Nakajima A et al. The disease pattern and causes of death of spinal cord injured patients in Japan. Paraplegia 1989; 27: 163 171

20 Rogers A, Rogers RG, Belanger A. Longer life but worse health? Measurement and dynamics. The Gerontologist 1990; 30: 640649.

21 Schroll M. Does increased life expectancy imply active life expectancy? Dan Med Bull 1992; 39: 258-261.
22 Verbrugge LM. Longer life but worsening health? Trends in health and mortality of middle aged and older persons. Health and Society 1984; 3: 475 - 519.

23 Statistics Canada. General Social Survey Analysis Series: Health and Social Support, 1985. Ministry of Supply and Services Canada: Ottawa 1987.

24 McColl MA, Rosenthal C. A model of resource needs of aging spinal cord injured men. Paraplegia 1994; 32: $261-270$.

25 Sullivan DF. A single index of mortality and morbidity. HSMHA Health Report 1971; 86: 347 - 354

26 Weinstein MC, Stason WB. Foundations of cost-effective analysis for health and medical practices. New England Journal of Medicine 1977; 296: 716-721.

27 Gelber RD, Goldhirsch A. New endpoint for the assessment of adjuvant therapy in postmenopausal women with operable breast cancer. Journal of Clinical Oncology 1986; 4: 1772 - 1779.

28 Reynolds DL et al. Modelling the population health impact of musculoskeletal diseases: Arthritis. Journal of Rheumatology 1993; 20: $1037-1047$

29 Statistics Canada. Health and Activity Limitations Survey, 1991. Ministry of Supply and Services Canada: Ottawa 1991.

30 Ritchie K, Robine JM, Letenneur L, Dartigues JF. Dementiafree life expectancy in France. American Journal of Public Health 1994; 2: $232-236$.

31 Glasziou PO, Simes RJ, Gelber RD. Quality adjusted survival analyses. Statistics in Medicine 1990; 9: 1259-1276.

32 Papsidero JA. Hypertension, quality of life and functional status. The concept of active life expectancy. Journal of Hypertension 1988; 6 (suppl 1): S11-S14.

33 Durance J. Health records of Kingston General Hospital. 1994 Unpublished raw data.

34 McColl MA, Walker J. Survival following spinal injury. 1991. Unpublished final report of 1991 study funded by A.T. Jousse Foundation.

35 McColl MA, Walker J, Stirling P. Quality-adjusted expectation of life following spinal cord injury. 1992. Unpublished final report of 1992 study funded by A.T. Jousse Foundation.

36 Stirling P. Update of mortality analysis of spinal cord injured individuals at Lyndhurst from 1980-1990. 1988. Unpublished raw data.

37 Chappell N, Strain L, Blandford A. Aging and health care: A social perspective. Holt, Rinehart and Winston of Canada, Ltd. Toronto 1986.

38 Collett D. Modelling survival data in medical research. Chapman \& Hall: London 1994.

39 Willett JB, Singer JD. Application of survival analysis to aging research. Experimental Aging Research 1991; 4: 243 - 250.

40 Krause JS, Crewe NM. Long-term prediction of self-reported problems following spinal cord injury. Paraplegia 1990: 28: $186-$ 202.

41 Gerhart K, Weitzenkamp D, Charlifue S. The old get older. Caliper 1996: $22-24$. 